\title{
Absent right superior vena cava with persistent left superior vena cava in a patient with COVID-19
}

\author{
Hiroshi Araki ${ }^{1} \cdot$ Motohiro Sekino $^{1}$ (1) $\cdot$ Naoya Iwasaki $^{1} \cdot$ Miki Suzumura $^{1} \cdot$ Takashi Egashira $^{1} \cdot$ Rintaro Yano $^{1}$. \\ Sojiro Matsumoto ${ }^{1} \cdot$ Ushio Higashijima $^{1} \cdot$ Takashi Sugimoto $^{2} \cdot$ Hirotomo Yamanashi $^{2,3,4} \cdot$ Tetsuya Hara $^{1}$
}

Received: 23 April 2021 / Accepted: 10 August 2021 / Published online: 16 August 2021

(c) The Japanese Society for Artificial Organs 2021

\begin{abstract}
Vascular injury associated with cannulation during extracorporeal membrane oxygenation (ECMO) induction is a rare but life-threatening complication. The presence of abnormal vascular anatomy increases the risk of vascular injury and should be recognized before cannulation. We report the case of a patient with coronavirus disease (COVID-19) who was expected to undergo ECMO. By performing computed tomography (CT), we identified the absence of right superior vena cava (RSVC) with a persistent left superior vena cava (PLSVC) that could have caused serious complications associated with ECMO cannulation. PLSVC is observed in less than $0.5 \%$ of the general population; however, the combination of PLSVC and an absent RSVC in visceroatrial situs solitus is extremely rare. Attempting cannulation for Veno-venous (VV)-ECMO from the right (or left) internal jugular vein to the right atrium may cause serious complications. Cannulation may fail or lead to complications even in patients with inferior vena cava malformations. Although these vascular abnormalities are rare, it is possible to avoid iatrogenic vascular injury by identifying their presence in advance. Since anatomical variations in the vessels from the deep chest and abdominal cavity cannot be visualized using chest radiography and ultrasonography, we recommend CT, if possible, for patients with severe respiratory failure, including those with COVID-19, who may be considered for VV-ECMO induction.
\end{abstract}

Keywords Extracorporeal membrane oxygenation $\cdot$ Cannulation $\cdot$ Computed tomography $\cdot$ Complication $\cdot$ Vascular malformation

Coronavirus disease (COVID-19) is an infectious disease caused by severe acute respiratory syndrome coronavirus 2 (SARS-CoV-2), which has spread worldwide [1].

Hiroshi Araki

hiroshi-araki@nagasaki-u.ac.jp

Motohiro Sekino

m-sekino@nagasaki-u.ac.jp

1 Department of Anesthesiology and Intensive Care Medicine, Nagasaki University Graduate School of Biomedical Sciences, 1-7-1 Sakamoto, Nagasaki 852-8501, Japan

2 Department of Infectious Diseases, Nagasaki University Hospital, Nagasaki, Japan

3 Department of General Medicine, Nagasaki University Hospital, Nagasaki, Japan

4 Department of Clinical Medicine, Institute of Tropical Medicine, Nagasaki University, Nagasaki, Japan
Veno-venous extracorporeal membrane oxygenation (VVECMO) has been reported to reduce mortality due to severe respiratory failure resulting from COVID-19 [2]. However, vascular injury complications comprise $0.74-1 \%$ of ECMO cannulations [3, 4], and once a vascular injury complication occurs, it is associated with patient mortality [5]. There is a risk of vascular injury when performing ECMO cannulation in patients with complicated vascular malformations.

With the consent of the patient, we report the case of a patient with COVID-19 who was expected to undergo ECMO; however, on performing computed tomography (CT), we identified an exceptionally rare vascular anatomical abnormality, an absent right superior vena cava (RSVC) with a persistent left superior vena cava (PLSVC). 


\section{Case report}

A 68-year-old man who had never been diagnosed with vascular malformations complained of dyspnea and fever for 3 days. One day before admission, his dyspnea worsened, and his throat swab sample yielded a positive result for the SARS-CoV-2 real-time reverse transcription polymerase

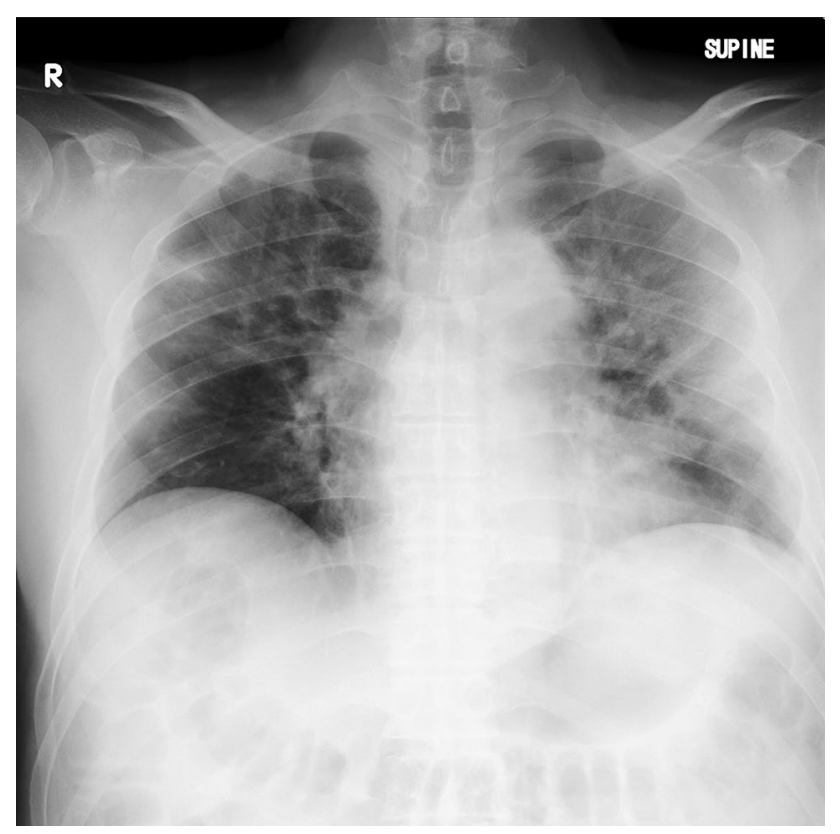

Fig. 1 The chest X-ray on admission revealed ground-glass opacities in the right upper lung field and left upper and lower lung fields; however, no other abnormalities were found chain reaction test. He was admitted to a hospital, where he was treated with dexamethasone and remdesivir. However, he required intensive care because of worsening oxygenation and respiratory failure and was transferred to our hospital on the ninth day after he developed COVID-19. His medical history included hypertension and dyslipidemia. Upon arrival to the hospital, his blood pressure was $110 / 79 \mathrm{~mm}$ $\mathrm{Hg}$, heart rate $95 \mathrm{bpm}$, and respiratory rate 28/min, with an oxygen saturation of $93 \%-95 \%$ with a resultant oxygen requirement of $8 \mathrm{~L}$ using a non-rebreather mask. His chest $\mathrm{X}$-ray on admission revealed ground-glass opacities in the right upper lung field and left upper and lower lung fields (Fig. 1).

Contrast-enhanced CT from the neck to the pelvis was performed to study the patient's lung condition, to detect thromboembolism, and to confirm that we could safely cannulate his blood vessels before VV-ECMO induction. The CT scan revealed that the patient had a complicated absent RSVC with PLSVC (Fig. 2). After the CT scan, his respiratory status rapidly deteriorated. The ratio of arterial partial pressure of oxygen to fraction of inspired oxygen $\left(\mathrm{FiO}_{2}\right)$ was $102 \mathrm{mmHg}$ under a high-flow nasal cannula (HFNC), with a gas flow of $60 \mathrm{~L} / \mathrm{min}$ and an $\mathrm{FiO}_{2}$ of 0.6. In addition to severe respiratory failure, the patient developed septic shock requiring norepinephrine and was admitted to the intensive care unit (ICU). A central venous catheter was placed into the right femoral vein to avoid vascular injury associated with catheter insertion because of PLSVC and absent RSVC. After admission to the ICU, tocilizumab, remdesivir, and nafamostat mesylate as an anticoagulant were administered. The treatment was altered from dexamethasone to hydrocortisone for acute respiratory distress syndrome and septic
Fig. 2 Three-dimensional computed tomography scans in the anteroposterior (a) and posteroanterior views (b) showing absent right superior vena cava (*) and persistent left superior vena cava (white arrows). The persistent left superior vena cava drains into the right atrium through the coronary sinus. The inferior vena cava (black arrows) is normal and leads to the right atrium
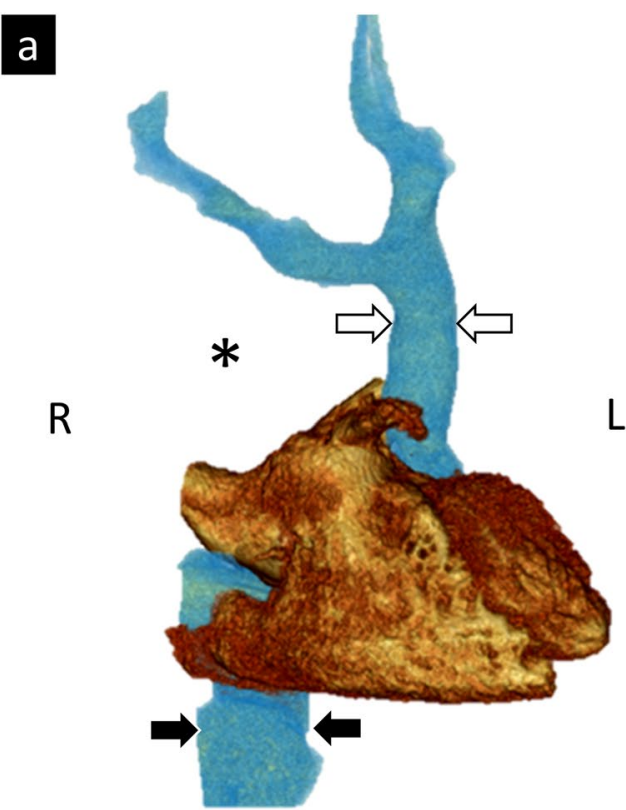
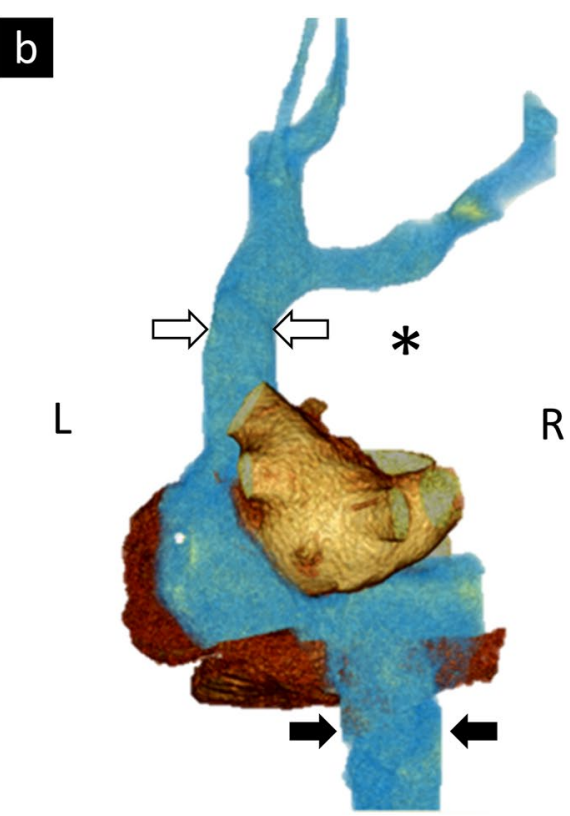
shock. Considering the complication of bacterial pneumonia, piperacillin-tazobactam was also administered. Awake prone position therapy with HFNC was introduced to prevent ECMO induction. His oxygenation gradually improved, and the ECMO induction was no longer necessary. He continued to recover well, and was weaned from the HFNC on the sixth day of hospitalization, and no longer required oxygenation on the 18th day; he was discharged on the 28th day.

\section{Discussion}

We report a case of severe respiratory failure associated with COVID-19, which was complicated with absent RSVC with PLSVC. Without the identification of this anatomical abnormality, cannulation for ECMO may have resulted in serious complications. It is important to confirm the existence of anatomical abnormalities in the vessel by CT imaging, if possible, in patients who are expected to undergo ECMO.

PLSVC is observed in less than $0.5 \%$ of the general population [6]; however, the combination of PLSVC and absent RSVC in visceroatrial situs solitus is extremely rare. Absent RSVC with PLSVC occurs in $0.09-0.13 \%$ of postmortem cases with congenital heart disease and 0.07-0.15\% of patients with pacemaker implantation [7-9]. Attempting cannulation for VV-ECMO from the right (or left) internal jugular veins to the right atrium, without recognizing this anomaly in such patients may cause serious complications.

Complications related to ECMO cannulation occur sometimes; one of the rarest but most serious complications is cannulation-related cardiac or major vascular perforation [3-5]. Ultrasonography, which has the advantage of being available at the bedside, is used to evaluate the vessels at the puncture site and to provide guidance in the event of a puncture. However, it is not possible to evaluate the vessels in the deep chest or deep abdominal cavity. Transesophageal echocardiography (TEE) is useful for guiding the cannulation of VV-ECMO [10], although its usefulness is limited in the deep chest cavity. Complications are reported to occur during ECMO cannulation owing to inferior vena cava (IVC) malformations [11]; thus, it is necessary to pay attention to not only SVC but also IVC vascular abnormalities. Vascular malformations in the deep chest and deep abdominal cavity cannot be visualized by chest radiography and ultrasonography, including TEE. Fluoroscopy is also used to ensure safety during catheter insertion. However, in case of a sudden deterioration in oxygenation, ECMO must be introduced at bedside; performing fluoroscopy is difficult. Moreover, the disadvantages of fluoroscopy include the risk of infection to medical staff and other patients during emergency transport to the angiography room in patients with COVID-19. In such cases, prior CT imaging is useful for safe cannulation.
Several studies that examined whether CT scan before cardiovascular surgery reduced complications showed that the CT imaging group changed the cannulation site for cardiopulmonary bypass and reported reduced complications $[12,13]$. Chest CT has also been reported to have a high sensitivity in diagnosing COVID-19 [14, 15]. In patients with severe respiratory failure, including those with COVID-19 and suspected COVID-19, who are expected to undergo ECMO, CT imaging is helpful to evaluate SVC and IVC during diagnosis and assessing lung status. The disadvantages of CT scans include the risk of infection to medical staff and other patients during transport in patients with COVID-19 and the cost of CT imaging. It is necessary to use each medical device according to the current situation of each medical facility.

When the patient required ECMO, we considered performing a femoro-femoral cannulation for VV-ECMO induction. The femoro-femoral VV-ECMO with cannulation of both femoral veins can be performed even in the presence of complications such as PLSVC with an RSVC defect, as noted in our patient [16]. Without prior CT imaging, we would have performed cannulation from the right internal jugular vein, which could have resulted in serious complications.

In conclusion, we present a case of severe respiratory failure associated with COVID-19, which was complicated with absent RSVC with PLSVC. Without recognizing this anatomical abnormality, cannulation for ECMO may result in serious complications. In patients who are expected to undergo ECMO, it may be imperative to confirm the presence of vascular anatomical abnormalities with prior $\mathrm{CT}$ imaging, if possible, as in patients of cardiovascular surgery.

Acknowledgements We would like to thank Editage (www.editage.jp) for English language editing and Yoshiaki Fukushima for his assistance with $3 \mathrm{D}$ reconstruction of the computed tomography images.

Author contributions All the authors were directly involved in patient treatment. HA conceived the case report and wrote the original draft. MS supervised the whole treatment and revised the manuscript. TH revised the manuscript and provided final approval to the version to be published. All the authors reviewed and edited the manuscript, and approved the final version of the manuscript.

\section{Declarations}

Conflict of interest None of the authors has any conflict of interest to declare.

Ethics approval This report was approved by the Institutional Review Board of Nagasaki University Hospital (Approval Number: 21021531).

Informed consent Written informed consent for publication was granted by the patient.

Field of research Artificial Lung/ECMO. 


\section{References}

1. Guan WJ, Ni ZY, Hu Y, Liang WH, Ou CQ, He JX, Liu L, Shan H, Lei CL, Hui DSC, Du B, Li LJ, Zeng G, Yuen KY, Chen RC, Tang CL, Wang T, Chen PY, Xiang J, Li SY, Wang JL, Liang ZJ, Peng YX, Wei L, Liu Y, Hu YH, Peng P, Wang JM, Liu JY, Chen Z, Li G, Zheng ZJ, Qiu SQ, Luo J, Ye CJ, Zhu SY, Zhong NS; China Medical Treatment Expert Group for Covid-19. Clinical characteristics of coronavirus disease in China. N Engl J Med. 2020;382:1708-20.

2. Shaefi S, Brenner SK, Gupta S, O'Gara BP, Krajewski ML, Charytan DM, Chaudhry S, Mirza SH, Peev V, Anderson M, Bansal A, Hayek SS, Srivastava A, Mathews KS, Johns TS, Leonberg-Yoo A, Green A, Arunthamakun J, Wille KM, Shaukat T, Singh H, Admon AJ, Semler MW, Hernán MA, Mueller AL, Wang W, Leaf DE; STOP-COVID Investigators. Extracorporeal membrane oxygenation in patients with severe respiratory failure from COVID19. Intensive Care Med. 2021;47:208-21.

3. Conrad SA, Grier LR, Scott LK, Green R, Jordan M. Percutaneous cannulation for extracorporeal membrane oxygenation by intensivists: a retrospective single-institution case series. Crit Care Med. 2015;43:1010-5.

4. Johnson SM, Itoga N, Garnett GM, Kilcommons M, Puapong DP, Woo RK. Increased risk of cardiovascular perforation during ECMO with a bicaval, wire-reinforced cannula. J Pediatr Surg. 2014;49:46-9.

5. Tanaka D, Hirose H, Cavarocchi N, Entwistle JW. The impact of vascular complications on survival of patients on venoarterial extracorporeal membrane oxygenation. Ann Thorac Surg. 2016;101:1729-34

6. Sonavane SK, Milner DM, Singh SP, Abdel Aal AK, Shahir KS, Chaturvedi A. Comprehensive imaging review of the superior vena cava. Radiographics. 2015;35:1873-92.

7. Bartram U, Van Praagh S, Levine JC, Hines M, Bensky AS, Van Praagh R. Absent right superior vena cava in visceroatrial situs solitus. Am J Cardiol. 1997;80:175-83.

8. Lenox CC, Zuberbuhler JR, Park SC, Neches WH, Mathews RA, Fricker FJ, Bahnson HT, Siewers RD. Absent right superior vena cava with persistent left superior vena cava: implications and management. Am J Cardiol. 1980;45:117-22.

9. Biffi M, Boriani G, Frabetti L, Bronzetti G, Branzi A. Left superior vena cava persistence in patients undergoing pacemaker or cardioverter-defibrillator implantation: a 10-year experience. Chest. 2001;120:139-44.

10. Teran F, Burns KM, Narasimhan M, Goffi A, Mohabir P, Horowitz JM, Yuriditsky E, Nagdev A, Panebianco N, Chin EJ, Gottlieb M, Koenig S, Arntfield R. Critical care transesophageal echocardiography in patients during the COVID-19 pandemic. J Am Soc Echocardiogr. 2020;33:1040-7.

11. Yeung Ng P, Wong CC, Young K, Kwong YY, Sin WC. Complication of venovenous extracorporeal membrane oxygenation cannulation - the significance of an inferior vena cava anomaly. Clin Case Rep. 2016;4:1132-4.

12. Lapar DJ, Ailawadi G, Irvine JN, Lau CL, Kron IL, Kern JA. Preoperative computed tomography is associated with lower risk of perioperative stroke in reoperative cardiac surgery. Interact Cardiovasc Thorac Surg. 2011;12:919-23.

13. den Harder AM, de Heer LM, Meijer RC, Das M, Krestin GP, Maessen JG, Bogers AJ, de Jong PA, Leiner T, Budde RP. Effect of computed tomography before cardiac surgery on surgical strategy, mortality and stroke. Eur J Radiol. 2016;85:744-50.

14. Fang Y, Zhang H, Xie J, Lin M, Ying L, Pang P, Ji W. Sensitivity of chest CT for COVID-19: comparison to RT-PCR. Radiology. 2020;296:E115-7.

15. Kovács A, Palásti P, Veréb D, Bozsik B, Palkó A, Kincses ZT. The sensitivity and specificity of chest CT in the diagnosis of COVID19. Eur Radiol. 2020;31:1-6.

16. Burrell AJC, Ihle JF, Pellegrino VA, Sheldrake J, Nixon PT. Cannulation technique: femoro-femoral. J Thorac Dis. 2018;10:S616-23.

Publisher's Note Springer Nature remains neutral with regard to jurisdictional claims in published maps and institutional affiliations. 